\title{
O DESIGN DA INFORMAÇÃO NAS ESTRATÉGIAS E MÉTODOS DE DESIGN THINKING APLICADOS AO ENSINO FUNDAMENTAL
}

\author{
lara D'Ávila Zorzal \\ Universidade do Estado de Minas Gerais \\ iarazorzal@gmail.com \\ Sebastiana Luiza Bragança Lana \\ Universidade do Estado de Minas Gerais \\ sebastiana.lana@gmail.com \\ Ricardo Triska \\ Universidade Federal de Santa Catarina \\ ricardo.triska@gmail.com
}

Resumo: O artigo propõe estudar a importância do design da informação na aplicação de manuais instrucionais que auxiliam na fundamentação do design thinking inserido no ensino fundamental. Para alcançar tal compreensão, desenvolve-se um estudo sobre $o$ atual contexto educacional; o que precisa ser modificado e como o design pode atuar na transformação desse sistema. A descoberta de que a educação não tem acompanhado as mudanças sociais elencadas pela era da informação, levou diversos designers a desenvolver métodos que insiram o raciocínio processual do design na comunicação e desenvolvimento do conhecimento que se dá nas salas de aula. Consciente dessas ações elegeu-se dois programas; o Design for Change e o Design Thinking para educadores, com o propósito de analisar seus manuais e descobrir como eles, através do design da informação, alcançam os professores e se fazem compreendidos.

Palavras-chave: design da informação, design thinking, educação fundamental.

\begin{abstract}
This article proposes to study the importance of the information design in the application of instructional manuals that assist in the reasoning of design thinking added design in elementary school. To achieve this understanding, it develops a study on the current educational context; what needs to be modified and how design can work in the transformation of this system. The finding that education has not kept pace with the social changes listed by the information age, has led many designers to develop methods to enter the procedural reasoning design communication and knowledge development that occurs in the classroom. Aware of these actions, we selected two programs; the Design for Change and the Design Thinking for educators, in order to analyze their manuals and find out how they, through its information design, reach teachers and are understood.
\end{abstract}

Keywords: design information, design thinking, primary education. 


\section{INTRODUÇÃO}

A educação, encontra-se desconectada das mudanças vivencias pela sociedade, desde o final do século XX (ARANHA, 1990). Tal falta de conexão entre o que se aprende na sala de aula e o que se vivencia fora dela, tem prejudicado a formação de pessoas conscientes e preparadas para o mundo real (REINHARDT, 2007). Ou, no caso contrário, afastando os alunos da vivência escolar, obrigando-os a frequentarem o espaço, mas não atingindo suas mentes (HARPER et al, 1987).

As críticas ao sistema educacional vigente não são atuais, mas, mesmo assim, apontam-se poucas mudanças neste meio (PILLETI; PILLETI, 1996). Para transtornar tal cenário, muitos educadores embrenharam-se, ao longo do tempo, em pesquisas e aplicações pontuais, e contemporaneamente, destacam-se ações de designers, que aplicam o processo de design no desenvolvimento didático e pessoal de cada aluno (FONTOURA, 2002; TABAK, 2012).

Entre as vertentes do design, encontram-se o design thinking e o design da informação com?laplicações reais em diversas escolas do mundo. Ambos, mostram-se capazes de auxiliarem na construção de um novo sistema educacional, mais interrelacionado com a vida dos alunos (NITZSCHE, 2010; REINHARDT, 2007).

O presente artigo, portanto, propõe a compreensão de como se dá a inserção dessas?]formas de design no meio educacional. Assim, desenvolveu-se uma pesquisa sobre o contexto educacional vigente, aprofundando-se nas aplicações existentes do design dentro de escolas. Por fim, apontam-se dois programas pautados no design thinking, que, consequentemente, utilizam do design da informação para serem difundidos: Design for Change (DFC) e o Design Thinking para Educadores (DTE).

Em ambos, têm-se distribuição gratuita e indiscriminada de seus manuais, podendo ser?utilizados por qualquer educador. $\mathrm{O}$ artigo avança para uma análise do infodesign aplicado a cada um desses materiais, afinal a compreensão total autodidata da proposta se faz estritamente necessária para que ela seja empregada devidamente.

\section{CONTEXTO EDUCACIONAL}

A educação, desde sua origem, atrela-se à condição social, cultural e econômica na qual está inserida (Aranha, 1990; Fontoura, 2002; Little, 2000). Mais do que um reflexo da sua sociedade, ela se relaciona intrinsecamente com esta, sendo alimentada pelas mudanças ocorridas e, ao mesmo tempo, nutrindo o sistema,com a capacidade de propulsionar transformações ou mantê-lo inalterável (Aranha, 1990; Kandel, 1961).

$\mathrm{Na}$ história ocidental, foi durante a idade média que a educação ganhou o status de produto?escola, isolando os educandos da sociedade e controlando cada saber transmitido (HARPER et al, 1987, p. 26). Porém, foi a sociedade vigente a responsável pelo sistema educacional vigente, já que a revolução industrial exigiu um maior número de trabalhadores qualificados técnica e cientificamente (PILLETI; PILLETI, 1996, p. 98). Apesar deste movimento ter promovido a difusão das escolas públicas, permitindo um maior acesso à educação, manteve-se a distinção entre o ensino unicamente técnico para o povo, do que para a classe dominante, com aprofundamento intelectual (BITTAR; BITTAR, 2012; HARPER et al, 1987).

O estabelecimento da indústria como sistema econômico determinante, ressaltou a?necessidade de transformar o homem do campo em um operário, promovendo o desenvolvimento de um ensino baseado na repetição e opressão ao 
erro (TABAK, 2012). Mesmo desconsiderando os fatos de que a educação é utilizada como meio de controle para alimentar a manutenção de um sistema de castas velado (KANDEL, 1961), ainda há um segundo ponto a ser questionado em seu processo: a submissão da criatividade aos ensinos técnicos (ROBINSON, 1999).

Apesar de oriundos da era industrial, os estudantes de hoje não mais a vivem, sob o julgo das regras da indústria (TOFFLER, 1980). A sociedade vigente encontra-se na que vem sendo chamada de era da informação (REINHARDT, 2007). Esta rompe barreiras físicas e aprofunda-se em marcantes mudanças, levando as pessoas além da padronização; sincronização e centralização, às quais foram formadas a se acostumarem (TOFFLER, 1980). O sistema educacional, encontra-se portanto, defasado frente ao seu entorno social e às necessidades que o mesmo impinge (REINHARDT, 2007; ROBINSON, 1999), muito porque a própria sociedade ainda tenta se encontrar diante das mudanças presenciadas. Vive-se em um tempo de transição, no qual a antiga norma econômica e cultural tenta sobreviver à nova, que se impõe sem pedir licença (TABAK, 2012; TOFFLER, 1980).

A percepção de que a educação precisa ser renovada, não é exclusividade do século XXI.?]Desde que a escola foi instituída como conveniente ao estado, educadores e filósofos apontam críticas e opções diversas (ARANHA, 1990; FONTOURA, 2002; PILLETI; PILLETI, 1996). Porém, a atual consciência de que as barreiras físicas e sociais podem ser dissolvidas, agrava a necessidade de urgência destas modificações. Nessa frágil situação, descobre-se o design como possível ponte entre a escola de hoje e a desejada para o amanhã (FONTOURA, 2002).

O design apresenta-se como uma ferramenta para a transformação educacional, devido ao? ?seu caráter sistêmico e transversal (KRUCKEN, 2008; LANA, 2011; MORAES, 2008). Oriunda da era industrial, esta área viu-se encurralada diante da drástica mudança de cenário, sendo levada à rápida adaptação para sobreviver a um novo e imprevisível universo, repleto de diferentes códigos (MORAES, 2008). Impingido a criar soluções para questões de alta complexidade, inerentes à sociedade que está se formando, o design se viu compelido a desenvolver-se de forma transversal e holística, perpassando por diversas e distintas áreas. (KRUCKEN, 2008).

É possível, assim, perceber que o design tem um excelente histórico quanto à adaptação à sociedade da informação, sendo apto a orientar prováveis mudanças educacionais.

\subsection{Design thinking e Design da informação - contextos e aplicações educacionais}

Com as mudanças ocorridas na sociedade, o design se adaptou inflando-se e implodindo-se em diversas disciplinas(DZIOBCZENSKIET al, 2011). Hoje, tem-se o design macro, com suas características elementares, formado por seus órgãos específicos, os quais, individualmente, aprofundam-se em uma ou mais destas características. Entre estes, o design thinking tem se destacado dentro e fora dos meios empresariais e intelectuais (KIMBELL, 2009; PROTZEN, 2010).

Na realidade, ele sempre fez parte dos projetos desenvolvidos pelos designers, porém, a sua identificação foi responsável por acusar o design como uma atividade processual, abrindo o seu campo para muito além da área puramente projetual (BALEM et al, 2011; DZIOBCZENSKIET al, 2011). Tal assimilação, facilitou a transversalidade do design, o que permitiu ao designer aplicar sua visão sistêmica em diversas, e impensadas, áreas (BALEM et al, 2011), como a educação fundamental. 
Conscientes da importância que a educação exerce na formação, não só de indivíduos, mas também, de uma nação futura (ROBINSON, 1999), vários designers se embrenharam na jornada pela transformação do sistema educacional através do aproveitamento e adaptação de suas metodologia e processos (FONTOURA, 2002; TABAK, 2012). O Design for Change e o Design Thinking para Educadores, destacam-se entre os vários projetos que despontaram pelo mundo, por suas difusões em diversas nações e seus resultados positivos.

O Design for Change, DFC, foi criado em 2009 por KiraBirSethi, como um desafio escolar, ?? propondo às crianças que promovam mudanças em seu entorno a partir da utilização de uma metodologia pautada no design thinking (GRAVATÁ et al, 2013). Já a ferramenta Design Thinking para Educadores, DTE, foi desenvolvida em 2011, pela IDEO em conjunto com a Riverdale, e apresenta-se como um instrumento para modificar a forma de encarar os atuais desafios enfrentados pelos professores (INSTITUTO EDUCADIGITAL, 2013).

Outra área do design que, cada vez mais, se associa à educação é o design da informação,??pois constitui-se como um "planejamento do ensino-aprendizagem, incluindo atividades, estratégias, sistemas de avaliação e métodos" (FILATRO; PICONEZ, 2004). Antes de tudo é importante compreender o que é informação, comunicação e conhecimento. A informação se dá através da organização de dados, formando um elemento que se expressa através de um código, adquirindo um significado para o um intérprete (FILATRO; PICONEZ, 2004; POLONI, 2011). Já a comunicação acontece apenas quando firma-se um relacionamento entre o emissor, a mensagem e o receptor, sempre considerando as condições e características do último, o qual tem a liberdade de interpretar e assimilar a informação à sua maneira (REINHARDT, 2007). O conhecimento surge a partir das experiências adquiridas através da comunicação de uma informação (POLONI, 2011).

Assim, é possível compreender o infodesign como uma ferramenta democrática, que tem a?]função de promover e facilitar a absorção, compreensão e uso das informações destinadas a um público (FUJITA; FONTOURA, 2009; REDIG, 2004). Sua aplicação presencial, tanto na própria sala; quanto nos materiais utilizados, majora a absorção do conteúdo pelos alunos, pois age de forma a preparar a informação, tornando-a passível de ser utilizada com eficiência e efetividade (HORN, 1999).

Considerando-se que a "informação é uma construção cultural" (REINHARDT, 2007), fica?? clara a relação entre design da informação e educação, já que esta última também se faz responsável pela constituição, manutenção e/ou mutação de crenças e tradições (ARANHA, 1990). O uso desta disciplina nas transformações escolares, vem sendo corroborado pela expansão que causa na capacidade de enxergar, formando pessoas aptas a compreenderem, assimilarem e criarem mensagens visuais. (COUTINHO; LOPES, 2011). O infodesign, portanto, auxilia na percepção e diagnóstico dos problemas, seguindo com a avaliação e análise do uso de possíveis ferramentas, e por fim otimizando os sistemas e ações educacionais (ALQUETE; OLIVEIRA; CAMPELO, 2013).

Assim, o design da informação se faz, claramente, necessário à aplicação de quaisquer?métodos para a assimilação e melhoria do sistema educacional. Afinal, todo tipo de mudança implica na comunicação e, por conseguinte, geração de conhecimento a partir de uma informação adquirida (REINHARDT, 2007). 
Compreende-se então, que os programas citados dependem de um bom desenvolvimento do infodesign em seus manuais, para que consigam alcançar seu verdadeiro intento, "contagiar o mundo com transformações educacionais"1.

\section{O DESIGN DA INFORMAÇÃO APLICADO AOS MANUAIS DOS PROGRAMAS DESIGN FOR CHANGE E DESIGN THINKING PARA EDUCADORES}

Através do uso de diversas técnicas, o infodesign age no equilíbrio entre o visual e o funcional, valendo-se de agrupamentos, ritmos e identidades para atingir a harmonia entre todos os elementos e fechar-se em uma comunicação bem sucedida (POLONI, 2011).

Alguns autores deslocam, a partir do design da informação, o design instrucional, que surge? ?com uma proposta de maior personalização e adaptação do conteúdo, permitindo a reformulação do mesmo, a partir da comunicação entre os agentes, no caso professores e alunos (FILATO; PICONEZ, 2004). Propõem assim, que para conseguir agir dentro do meio educacional, deve-se conferir uma nova forma de design, que a partir de suas bases consolidadas agirá intencionalmente na configuração de situações didáticas específicas, comprometendo-se com a publicação instrucional, para que as soluções encontradas possam ser difundidas ou mesmo alteradas pelos seus receptores (FILATO; PICONEZ, 2004; REINHARDT, 2007).?

Consciente da sua importância, buscou-se identificar, em forma e função, os elementos? ?utilizados, nos manuais dos programas DFC e DTE. Considerando-se que o materiais analisados têm por finalidade instruir, a quaisquer pessoas que se interessem por eles, sobre a aplicação de seus métodos processuais, optou-se por unir o design da informação ao design instrucional. Tal determinação metodológica, deu-se a partir da noção de que ambos apresentam a multidisciplinaridade como característica inerente, aproximando-se em diversos pontos (ALQUETE; OLIVEIRA; CAMPELO, 2013; COUTINHO; LOPES, 2011).

Para desenvolver a metodologia que servirá à análise, tomou-se como base o estudo de?Alquete; Oliveira e Campelo (2013), que resultou em tabelas comparativas do design da informação e instrucional. Apresentas, a seguir, como quadros 1 e 2:

Quadro 1 - Metodologia Processual: Design da Informação (BOSWOOD, 2002) x Design Instrucional execução (FILATRO, 2008).

\begin{tabular}{|l|l|l|}
\hline ETAPAS & DESIGN DA INFORMAÇÃo & DESIGN INSTRUCIONAL \\
\hline $\mathbf{1}$ & (1) Planejar da informação; & (1) Analisar a necessidade; \\
\hline $\mathbf{2}$ & (2) Planejar o projeto & (2) Planejar a solução \\
\hline $\mathbf{3}$ & $\begin{array}{l}\text { (3) Selecionar o conteúdo/organização/ design } \\
\text { (4) Realizar rascunhos/testes }\end{array}$ & (3) Desenvolver a solução \\
\hline $\mathbf{4}$ & (5) Produzir o projeto & (4) Implementar a solução \\
\hline $\mathbf{5}$ & (6) Continuar o processo & (5) Avaliar a solução \\
\hline
\end{tabular}

Fonte: ALQUETE; OLIVEIRA; CAMPELO, 2013

1 SETHI 2009. Kids, Take Charge. In: Home: TED.

<http://www.ted.com/talks/kiran_bir_sethi_teaches_kids_to_take_charge\#t-360726>, 04/12/2014 
Quadro 2 - Princípios em Design da Informação (REDIG, 2004) e Design Instrucional (FILATRO, 2008).

\begin{tabular}{|l|l|}
\hline DESIGN DA INFORMAÇÃO & DESIGN INSTRUCIONAL \\
\hline (A) Foco no receptor; & (A) Foco no aluno; \\
\hline (B) Analogia; & (B) Prática; \\
\hline (C) Clareza; & (C) Coerência; \\
\hline (D) Concisão; & (D) Redundância; \\
\hline (E) Ênfase; & (E) Multimídia; \\
\hline (F) Coloquialidade; & (F) Personalização; \\
\hline $\begin{array}{l}\text { (G) Consistência; } \\
\text { (G) Estabilidade }\end{array}$ & $\begin{array}{l}\text { (G) Proximidade } \\
\text { Espacial; } \\
\text { (H) Cordialidade; }\end{array}$ \\
\hline (I) Oportunidade; & \multicolumn{2}{|l}{ (G)dalidade; } \\
\hline
\end{tabular}

Fonte: ALQUETE; OLIVEIRA; CAMPELO, 2013

O quadros 1 e 2 definem o design da informação como puramente empresarial, enquanto o? ?design instrucional foca-se no universo da educação. Porém, são retirados pontos importantes para o aprimoramento da aplicação do processo pretendido, ao se desassociar o design instrucional do informacional, ficando o último sem o desenvolvimento de sketches e/ou rascunhos. O processo de testes antes da aplicação, é o que diferencia o designer de um leigo com uma ótima ideia (BALEM et al, 2011; DESING COUNCIL). É neste momento que se aplica a visão sistêmica, verificando-se as possíveis decorrências, positivas e negativas, em todos os campos que cercam a mudança pretendida (CASAS; STRAIOTO; SOUSA, 2010).?

No caso do quadro 2, encontram-se, em ambos lados, pontos significativos à? lincorporação dos conteúdos pelo receptor. Afinal, para preparar as pessoas para viverem em uma complexa sociedade é preciso criar métodos avançados, capazes de transporem à mente dos alunos e transformarem informação em saber, estimulando a replicação do que está sendo ensinado e construído (REINHARDT, 2007). Propõe-se, através da figura 1 , a seguinte relação:

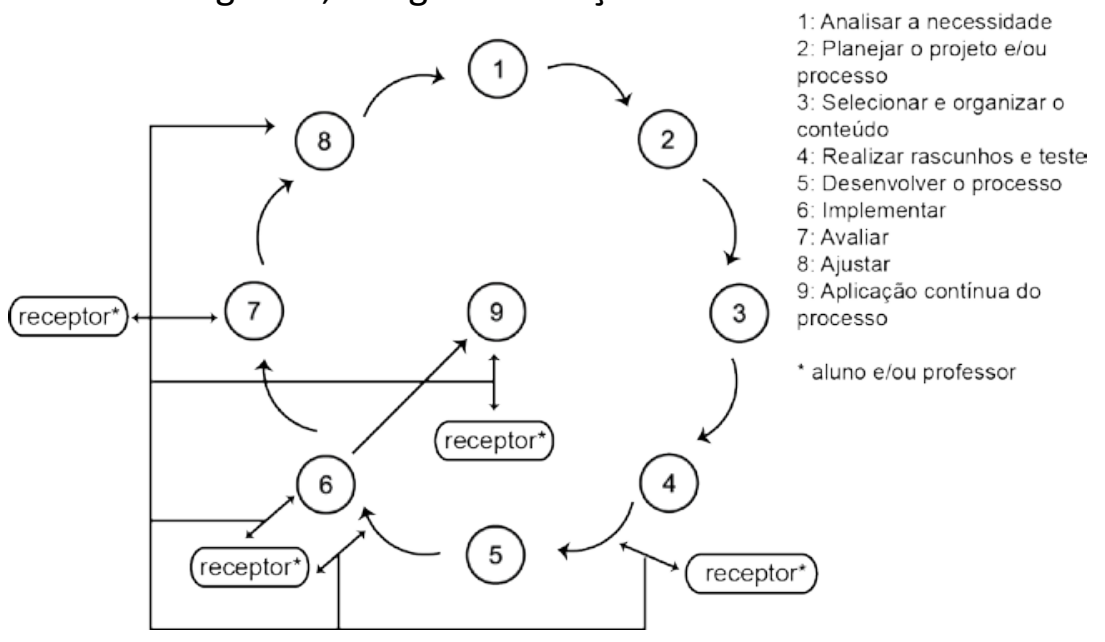

Figura 1 - Design da informação como processo educacional.

Fonte: Elaborado pelos autores com base na pesquisa realizada 
Seguindo o processo sugerido acima, fundem-se os elementos exibidos, ??anteriormente, nos quadros 1 e 2, com o propósito de proporcionar maior fluidez e rendimento à aplicação do design da informação. Como sugerido, no quadro 3:

Quadro 3 - Pontos a serem analisados do design da informação desenvolvido nos manuais dos programas Design for Change e Design Thinking para Educadores.

\begin{tabular}{|l|}
\hline DESIGN DA INFORMAÇÃO COMO PROCESSO EDUCACIONAL \\
\hline (A) Foco no receptor = professor e/ou aluno; \\
\hline (B) Analogia; \\
\hline (C) Capacidade Prática \\
\hline (C) Clareza e Coerência; \\
\hline (D) Concisão; \\
\hline (E) Ênfase e Redundância; \\
\hline (F) Coloquialidade e Personalização; \\
\hline (G) Consistência e Estabilidade; \\
\hline (H) Adequação à sociedade inserida e capacidade de se adaptar; \\
\hline (I) Cordialidade; \\
\hline (J) Oportunidade; \\
\hline
\end{tabular}

Fonte: Elaborado pelos autores com base na pesquisa realizada

A partir do proposto identifica-se o infodesing como processo educacional, alcançando o status?]de personalizável e atento ao meio que está inserido. Seguem-se, as análises dos manuais visando desenvolver um melhor entendimento na aplicação destes programas à luz do design da informação.

\subsection{Design for Change}

O DFC já alcançou "35 países, inspirando mais de 25 milhões de crianças e adolescentes ao redor do mundo" (CRIATIVOS DA ESCOLA, 2016, p. 2), e chegou ao Brasil em 2012, como Design for Change Brasil. Após três anos de testes, em 2015, seu nome foi modificado para Criativos da Escola, desmistificando a origem estrangeira e se estabelecendo nacionalmente. Sendo indiano e difundido largamente pelo mundo, existem diversos tipos de manuais para auxiliarem projetos escolares com base na metodologia desenvolvida por Sethi (GRAVATÁ et al, 2013). Portanto, decidiu-se analisar apenas o manual adaptado para o Brasil, evitando lacunas na pesquisa por falta de informações culturais.

O material, reformulado em 2016, é distribuído gratuita e indiscriminadamente através do site criativosdaescola.com.br. Composto com uma linguagem uniformizada e organizada, dispõem-se trezes passos distribuídos em quatro etapas principais: Sentir, Imaginar, Fazer e Compartilhar (CRIATIVOS DA ESCOLA, 2016). Todas as fases são elucidadas por meio de explicação textual e apresentam descrição de tempo, continuidade, material, formação de grupo e dicas.

O quadro 3 foi construído a partir dos estudos apresentados?e serviu de base para as próximas análises, em busca da compreensão de como se deu o desenvolvimento do infodesign aplicado ao manual. Assim, leu-se cada parte, pontuando os dados necessários e conduzindo a seguinte percepção.

O uso predominante de textos médios, tipografia asserifada, poucos recursos imagéticos, e uma paleta de cores pautada no azul, vermelho, roxo e escala de cinza, indicam o professor como receptor principal, e o aluno como secundário. O leve 
equilíbrio provocado por grafismos e um tipografia complementar de traço irregular, traz jovialidade ao projeto e cordialidade ao se estabelecer um vínculo com as crianças e adolescentes (receptores secundários).

Verifica-se, facilmente, cada informação apresentada, bem como a hierarquia entre elas. O?que indica a presença de clareza e coerência na linguagem, no projeto gráfico e na distribuição dos dados, conferindo ao manual um boa leiturabilidade. Por apontar-se direto e de fácil compreensão, a leitura é agilizada, facilitando a sua aplicação e permitindo ao professor descobrir o que precisa com rapidez.

Com uma linguagem simples, o manual não se limita aos intelectuais, sendo capaz de se adequar às condições brasileiras, podendo ser aplicado tanto em escolas públicas, quanto por ONG's em centros menos privilegiados, ou mesmo na educação do campo. Além disso, o material é cordial ao se abrir para receber ideias de atualização e/ou responder à possíveis dúvidas, apresentando-se de forma democrática e aberta à adaptações e personalizações.

Por fim, retomando a análise de figuras, inclue-se o pictograma utilizado para indicação capitular. Formado por um retângulo (ou seta) com vários pares de pernas, desenvolve-se a analogia do trabalho em grupo, bem como da mundialização do movimento DFC Apesar de aberto a modificações, a redundância dos dados básicos, apontam a consistência e estabilidade dos valores e técnicas definidos por Sethi, em 2009. O manual apresenta-se assim, com uma base sólida capaz de permitir adaptações sem perder seu real objetivo durante as aplicações.

Apesar de promover o compartilhamento dos projetos com a comunidade, e de já ter sido coberto por diversas mídias de massa, ainda é preocupante que o material só possa ser encontrado na internet. Tal característica dificulta seu acesso à maioria das pessoas marginalizadas, mantendo-o recluso às instituições com as quais o Criativos da Escola desenvolveu algum diálogo.

\subsection{Design Thinking para Educadores}

Originalmente Design Thinking for Educators, o programa chegou ao Brasil em 2013, através de uma parceria entre a IDEO e o Instituto Educadigital (INSTITUTO EDUCADIGITAL, 2013). Este, forma-se em um completo livro de 89 páginas, mais capa e contra-capa, sendo dividido em quatro partes: 1. Depoimentos e explicações sobre o projeto; 2. Fundamentação teórica do programa; 3. Passo a passo para o desenvolvimento do processo metodológico; 4. Anexo que resume todo o caderno.

Disponibilizado, para download gratuito, pelo site: dtparaeducadores.org.br, o material? ?encontra-se licenciado pela Creative Commons Attribuition - Non Comercial . Pode, assim, ser compartilhado e remixado por quaisquer pessoas, contanto que não seja comercializado e deem o crédito exigido.

Apesar de maior, com mais ilustrações e informações do que o manual do Criativos da Escola, a metodologia apresentada é muito parecida com a do anterior, como mostrado no quadro 4:

Quadro 4 - Fases dos processos desenvolvidos pelos programas Design for Change e Design Thinking para Educadores. 


\begin{tabular}{|l|l|}
\hline DESIGN FOR CHANGE & DESIGN THINKING PARA EDUCADORES \\
\hline Sentir & Descoberta \\
\hline Imaginar & $\begin{array}{l}\text { Interpretação } \\
\text { Ideação }\end{array}$ \\
\hline Fazer & Experimentação \\
\hline Compartilhar & Evolução \\
\hline
\end{tabular}

Fonte: Elaborado pelos autores com base na pesquisa realizada

Observando o quadro 4, vê-se que fases apresentadas findam-se nos mesmos princípios,?]tendo apenas nomenclaturas diferenciadas. Sugere-se assim, que ambos programas são originados da mesma disciplina de design, o Design Thinking.

Com uma identidade bem definida pelas cores, tipografias e ilustrações utilizadas. O livro-? ?manual apresenta-se como um produto completo, que fornece suporte ao professor tanto nos momentos de preparação da aula, quanto durante as aplicações, tendo cada parte destinada ao seu correto momento.

$O$ desenvolvimento do projeto é descrito minunciosamente, e o infodesign desenvolvido?distribui as informações de maneira clara e hierárquica, valendo-se do uso de pictogramas para equilibrar a páginas, que trazem muitos dados escritos. Assim como no item anterior, leu-se todo o manual para se desenvolver um análise sobre o mesmo, atingindo as seguintes respostas.

A partir de sentenças discursivas e interrogativas, o manual apresenta uma linguagem?direcionada ao professor, desenvolvendo uma conversa com o mesmo ao longo do livreto. A evolução das informações, também se dá a partir do uso de diversos pictogramas, desenvolvendo analogias que suavizam o excesso de dados transmitidos. Objetivando que o processo metodológico instruído tome corpo nas salas de aula, o manual traz, além da teoria, um passo a passo minucioso que ajuda os professores a executarem o projeto.

De forma bem aplicada o infodesign consegue exercer um equilíbrio visual, balanceando as?]informações escritas com ilustrações. Além disso, o detalhamento das descrições e teorias apresentadas, são distribuídos de forma hierárquica, utilizando-se de cores e variações tipográficas que contribuem para enfatizar as informações e manter a clareza no momento da leitura.

Criado pensando em ensinar o processo de design thinking aos leigos, o manual?apresenta muitos dados redundantes, ensinando-se a teoria e repetindo-a sempre que possível ao longo dos textos. Mesmo a parte teórica, não é escrita com jargões muito específicos da área do design, mantendo a limpidez no momento de ser compreendido por pessoas não formadas na área. Tal utilização da linguagem, de forma coloquial e direta, facilita a adaptação do manual à realidade na qual se encontra.

A metodologia é apresentada de forma consistente e estável por todo o projeto, sendo reafirmada a cada capítulo, garantindo que o processo será compreendido e reaplicado sem alterar as bases que o formam. $O$ excesso de descrição e explicação de como e porque funciona cada etapa, finda, então, na concepção de professores aptos a exercerem a liberdade adquirida, podendo alterar e ajustar o que sentirem necessidade.

Assim como o projeto apresentado anteriormente, a oportunidade não se encontra bem?trabalhada. Também distribuído somente pela internet, o projeto não consegue alcançar a maioria dos professores brasileiros, ficando preso em pequenos 
círculos.

Mesmo que ambos os manuais apresentados encontrem em seu projeto de design da?informação a mesma falha preocupante, vale lembrar que o momento é oportuno. Basta a esses, então, iniciarem um processo de democratização na distribuição de seus materiais, alcançando, assim, maiores áreas geográficas e sociológicas.

\section{CONCLUSÃO}

A partir das análises desenvolvidas e dos fatos apresentados ao longo do artigo, é possível afirmar que o design da informação apresenta-se não só como crucial para o desenvolvimento das mudanças educacionais, mas também responsável pela adaptação da sociedade à era da informação. Afinal, é o infodesign o responsável pela organização, assimilação e replicação de todas as comunicações imagéticas.

Assim, tomando-se como base as análises anteriores, pode-se afirmar que os programas?Design for Change (DFC) e Design Thinking para Educadores (DTE) mostram um design da informação bem desenvolvido em seus manuais. Com clareza nos dados apresentados, eles se portam, linguística e imageticamente, de maneira facilmente assimilável. Bem organizados, com ênfases hierárquicas entre as informações presentes, tais manuais conseguem ser lidos e compreendidos com naturalidade por leigos no assunto proposto. Portanto, são muito úteis e eficazes em atingirem o objetivo principal, explicar a quaisquer pessoas como praticar o design thinking como forma de ensino.

Diante da já estabelecida era da informação, a sociedade vem se modificando, abrindo-se para novos conceitos e buscando livrar-se das amarras construídas durante a hegemonia industrial. Para tanto, é preciso que a educação consiga libertar-se dos preceitos cartesianos, assimilando a criatividade como uma importante disciplina e rompendo barreiras como idade e classe social.

O design da informação mostra-se, a partir das ideias discutidas, capaz de auxiliar na?lassimilação desse novo estilo de ensino. Os manuais apresentados, evidenciam a ideia proposta, já que a distribuição linguística e imagética desenvolvidas permitem um maior acesso, e facilitam a compreensão de como proceder para agilizar a evolução desejada, cumprindo assim a missão do infodesign. Sua aplicação bem realizada, é, então, capaz de levar a educação a trabalhar para e com os alunos, e a sociedade.

\section{REFERÊNCIAS}

COUTINHO, Solange G.; LOPES, Maria Teresa.Design para educação: uma possível contribuição para o ensino fundamental brasileiro. In: BRAGA, Marcos da Costa (Org.) 0 papel social do design gráfico: história, conceitos e atuação profissional. São Paulo: Editora Senac, 2011. P. 137-162.

FILATRO, Andrea; PICONEZ, Stela Conceição Bertolo. Design instrucional contextualizado. In: FILATRO, Andrea. Design instrucional na prática.. São Paulo: Pearson, 2004. P. 14-23

HORN, Robert E. Information design: the emergence of a new profession. In: JACOBSON, R . Information Design. Cambridge: MIT Press, 1999. P. 15-34.

KRUCKEN, Lia. Competências para o design na sociedade contemporânea. In: MORAES, Djon De; KRUCKEN, Lia. Cadernos de Estudos Avançados do Design: Transversalidade. 
Minas Gerais: Editora da Universidade de Minas Gerais, 2008. P. 23-32.

LANA, Sebastiana Luiza Bragança. A complexidade dos métodos em design. In: MORAES, Djon De; DIAS, Regina Álvares; CONSELHO, Rosemary Bom. Cadernos de Estudos Avançados do Design: Método. Minas Gerais: Editora da Universidade de Minas Gerais, 2011. P. 53-66.

MORAES, Djon De. Design e Complexidade. In: MORAES, Djon De; KRUCKEN, Lia. Cadernos de Estudos Avançados do Design: Transveralidade. Minas Gerais: Editora da Universidade de Minas Gerais, 2011. P. 07-20.

ARANHA, Maria Lúcia de Arruda. Filosofia da educação. São Paulo: Moderna, 1990.

KANDEL, Isaac Leon. The new era in education: a comparative study. Rio de Janeiro: Editora Fundo de Cultura S.A, 1961.

GRAVATÁ, André et al. Volta ao mundo em 13 escola: sinais do futuro no presente. Rio de Janeiro: Editora Fundo de Cultura S.A, 2013.

PILETTI, Claudino; PILETTI, Nelson. História da educação. São Paulo: Editora Ática, 1996.

ROBINSON, Ken. All Our Futures: creativity, culture and education.New York: NACCE, 1999.

TOFFLER, Alvin. A terceira onda. Origninal: the third wave. Tradução João Távora. Rio de Janeiro: Editora Record, 1980.

FONTOURA, Antônio Martiniano. A educação de crianças e jovens através do design. 2002. 337 f. Tese (doutorado) - Universidade Federal de Santa Catarina, Curso de PósGraduação em Engenharia de Produção e Sistemas.

REINHARDT, Nancy Viviana. Infografía didáctica: producción interdisciplinaria de infografías didácticas para la diversidad cultural. 2007. 137 f. Dissertação (mestrado) Universidade de Palermo, Curso de Pós-Graduação em Design e Comunicação.

TABAK, T. (não) Resolução de (não) problemas: contribuições do Design para os anseios da Educação em um mundo complexo. 2012. 99 f. Dissertação (mestrado) - Pontifícia Universidade Católicado Rio de Janeiro, Curso de Pós-Graduação em Artes \& Design.

POLONI, Rafael Wagner. A infografia como ferramenta auxiliar na aprendizagem. Trabalho de Conclusão de Curso (Monografia não publicada), Curso de Identidade Visual, Faculdade de Arquitetura da Universidade Federal do Rio Grande do Sul, 2011.

ALQUETE, Turla A.; OLIVEIRA, Raquel R. S.; CAMPELLO, Silvio B, Design da informação e instrucional para a educação: contribuições no desenvolvimento de artefatos digitais de aprendizagem. In: CONAHPA - CONGRESSO NACIONAL DE AMBIENTES HIPERMÍDIA PARA APRENDIZAGEM, 6. 2013, João Pessoa. Anais... João Pessoa:PB. P. 1-13.

BITTAR, Marisa; BITTAR, Mariluce.História da educação no Brasil: escola pública no processo de democratização da sociedade. Acta Scientiarum.Maringá, v.34, n.2, 2012. P. 157-168.

BALEM, Franciele Regina et al. Design thinking: conceitos e competências de um processo de estratégias direcionado a inovação. In: DESENHANDO O FUTURO, 10 CONGRESSO NACIONAL DE DESIGN, 1. 2011, Bento Gonçalves. Anais... Bento Gonçalves: DF. P. 1-13. 
CASAS, Diego Daniel; STRAIOTO, Ricardo Goulart Tredezini; SOUSA, Richard Perasi Luiz de Souza. Designers: entre céticos e dogmáticos. Design, Arte, Moda e Tecnologia. São Paulo, 2010. P. $378-388$.

DZIOBCZENSKI, Paulo Roberto Nicoletti et al. Inovação através do design: princípios sistêmicos do pensamento projetual. In: PGDESIGN: DESIGN E TECNOLOGIA, 3. 2011, Porto Alegre. Anais... Porto Algre: PDG. P. 54-63.

FUJITA, Patrícia Tieme Lopes; FONTOURA, Antônio Martiniano.O design da informação na Biblioteca Pública do Paraná: aplicação do sense-making e do wayfinding no estudo e análise do espaço informacional. Revista eletrônica SBDI. Curitiba, 2009. P. 8-16.

KIMBELL, Lucy. Beyond design thinking: design as practice and design in practice. CRESC CONFERENCE, 5. 2009, Manchester. Anais... Manchester:CRESC, 2009. P. 1-15.

NITZSCHE, Rique. Design thinking. Revista da ESPM. São Paulo, 2010. P. 124-126.

REDIG, Joaquim. Não há cidadania sem informação, nem informação sem design. Revista Brasileira de Design da Informação, v.1. São Paulo, 2004. P. 47-56.

PROTZEN, Jean Pierre. Design thinking: whats that? In: CAL DESIGN LAB LECTURE, 1. 2010, São Diego. Anais... São Diego: CDLL. P. 1-12.

DESIGN COUNCIL. What is design. Disponivel na internet por http em: <http://www.mech.hku.hk/bse/interdisciplinary/what_is_design.pdf >. Acesso em 19 abr. 2015.

INSTITUTO EDUCADIGITAL. Design Thinking para Educadores: versão em postugês. Disponível na internet por http em: <http://dtparaeducadores.org.br/site/>. Acesso em 05 jun. 2016?

ONG DESIGN FOR CHANGE BRASIL. Design for Change. Disponível na internet por http em: <http://www.dfcbrasil.com.br>. Acesso em 05 jun. 2016.

SETHI, Kiran Bir. Kids, Take Charge. Disponível na internet por http em: <http://www.ted.com/talks/kiran_bir_sethi_teaches_kids_to_take_charge\#t-360726>. Acesso em 04 dez. 2014

CRIATIVOS DA ESCOLA. Criativos da escola: design for change - material de apoio.

Disponível na internet por http em: < http://criativosdaescola.com.br/wp-

content/uploads/2016/04/manual_vers?o2016site-1.pdf>. Acesso em 01 jun. 2016 